\title{
NATURAL DYES AND THEIR FT-IR SPECTROSCOPY STUDIES
}

\author{
P.Priyadharsini ${ }^{1}$, S. Theodore David ${ }^{2}$, Joel ${ }^{3}$ \\ 1,2,3 Department of Chemistry, St.John's College Pallayamkottai. Tamil Nadu. India. \\ pdharsini49@gmail.com.
}

\section{Abstract}

The present study focuses on the extraction of Natural dyes from Curcuma longa, Allium cepa, Optuntia ficus-indica, Beta vulgaris, Hibiscus, Lawsonia inermis with improved properties for textile applications. The plant material was made in to the paste and was subjected to dryness to recover the dye in a pure powder form. The dyes were characterized by FT-IR spectroscopy.

Keywords: Natural dyes, FT-IR spectroscopy, Curcuma longa, Allium cepa, Optuntia ficus-indica, Betavulgaris, Hibiscus, Lawsoniainermis

\section{INTRODUCTION}

A dye is a colored substance that has an affinity to the substrate to which it is being applied. The dye is generally applied in an aqueous solution, and requires a mordant to improve the fastness of the dye on the fiber. Both dyes and pigments appear to be colored because they absorb some wavelengths of light more than others. In contrast with a dye, a pigment generally is insoluble, and has no affinity for the substrate.

An attempt has been made to extract some of the natural dyes from plants and study their spectral properties by FT-IR spectroscopy. The IR Spectra was recorded for all the samples, using Fourier Transform Infrared Spectroscopy (FTIR)-model No-4100 type A Serial No.C193061016. The FTIR Spectra have been recorded at the Chemistry Research Centre of PSN college of Engineering and Technology, Melathidiyoor, Tirunelveli, Tamil Nadu.

\section{A. Description of the Plants studied}

Turmeric (Curcuma longa) is a rhizomatous herbaceous perennial plant of the ginger family, Zingiberaceae. It is native to tropical South Asia as it was first discovered and used in Ancient India. It needs temperatures between $20^{\circ} \mathrm{C}$ and $30^{\circ} \mathrm{C}$ and a considerable amount of annual rainfall to thrive. Its active ingredient is curcumin and it has a distinctly earthy, slightly bitter, slightly hot peppery flavour and a mustardy smell.
Onion (Allium cepa) is the most widely cultivated species of the genus Allium. The genus Allium also contains a number of other species variously referred to as onions and cultivated for food widely in Central Asia.

Optuntia, also known as no pales or paddle cactus (see below), is a genus in the cactus family, Cactaceae. Currently, only prickly pears are included in this genus of about 200 species distributed throughout most of the Americas.

The most commonly culinary species is the Indian Optuntia (O. ficus-indica). The beetroot (Beta vulgaris) is a plant in the Chenopodiaceae family which is now included in Amaranthaceae family. It is best known in its numerous cultivated varieties, the best known of which is the purple root vegetable known as the beetroot or garden beet.

Hibiscus is a genus of flowering plants in the mallow family, Malvaceae. It is quite large, containing several hundred species that are native to warm-temperate, subtropical and tropical regions throughout the world. Member species are often noted for their showy flowers and are commonly known as hibiscus, sorrel, and flor de Jamaica, or less widely known as rose mallow.

Henna (Lawsonia inermis), also called henna tree) is a flowering plant used since antiquity to dye skin, hair, fingernails, leather and wool. The name is also used for dye preparations derived from the plant, and for the art of temporary tattooing based on those dyes. Additionally, 
the name is misused for other skin and hair dyes, such as black henna or neutral henna, which are not derived from the plant.

\section{MATERIALS AND METHODS}

The solvent used for the extraction of the dyes from the plants is Acetone. It was purchased from Loba chemie in pure form and used as such. The materials required for the extraction of the dyes were freshly collected from root of Turmeric and beetroot leaves of Optuntia and henna, skin of Onion, flower of Hibiscus.

\section{A. Method of extraction}

$20 \mathrm{~g}$ of the plant material (root/ flower/skin/leaves) was weighed in a $400 \mathrm{ml}$ beaker. It was meshed to fine paste. $30 \mathrm{ml}$ acetone and $20 \mathrm{ml}$ water were added and stirred continuously for 30 minutes.

The contents were centrifuged and the sediments were discarded. The solution containing the dye was evaporated over a water bath. The dried powder was dissolved in acetone, filtered and evaporated again to get the dye in pure form. The dyes were characterized by FTIR spectroscopy.

\section{B. Spectral Characterization}

The seven dyes extracted and characterized by FTIR spectroscopy. The IR Spectra was recorded for all the samples, using Fourier Transform Infrared Spectroscopy (FTIR)-model No-4100 type A Serial No.C193061016.

\section{RESULTS AND DISCUSSION}

The spectral characteristics of the dyes prepared from turmeric, Onoin skin, opuntia, hibiscus, beetroot and mehandhi have been discussed in this section and are shown in Fig.1 to Fig.6 respectively. The spectral ranges obtained from FTIR have been used in identifying the components present in the dye extract. The dye present in turmeric is curcumin (Fig.1). The yellow dye in onion skin is made a of mixture of flavonoids: quercetin, Kempferol and quercetin-3-glucoside(Fig.2). Opuntia dye extract indicates structures of the flavanols, Kempferol and Catechin (Fig.3). Structures of the dye extracted from Hibiscus are Delphinidin 3-sambubioside (Fig.4). The dye extracted from Beetroot is Betanin, a betacyanin (Fig.5). The dye extracted from Henna leaves (Mehnthi), contains 2-Hydroxy-1, 4-naphthoquinone (Fig.6).

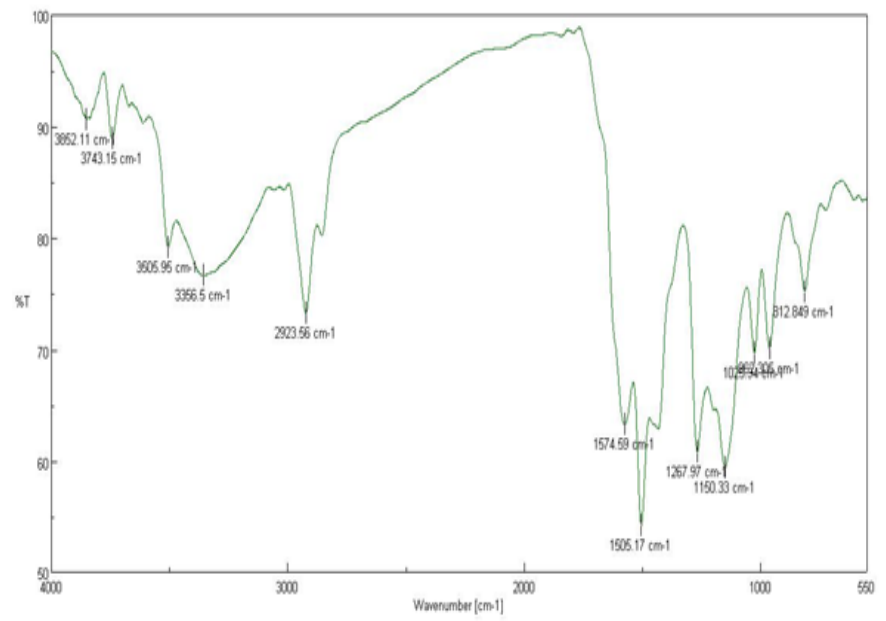

Fig.1. FTIR Spectrum of Turmeric dye

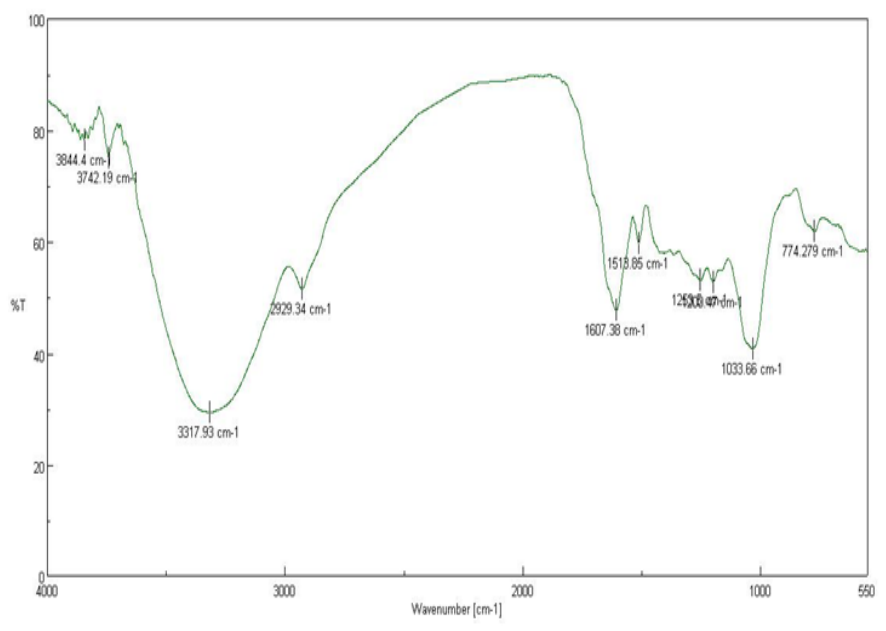

Fig. 2. FTIR Spectrum of onion skin dye 


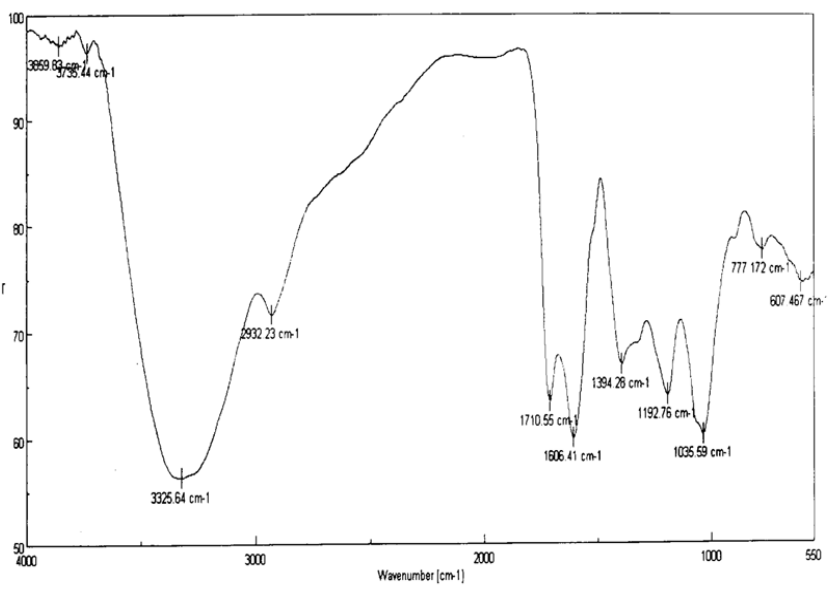

Fig. 3 . FTIR Spectrum of Optuntia dye

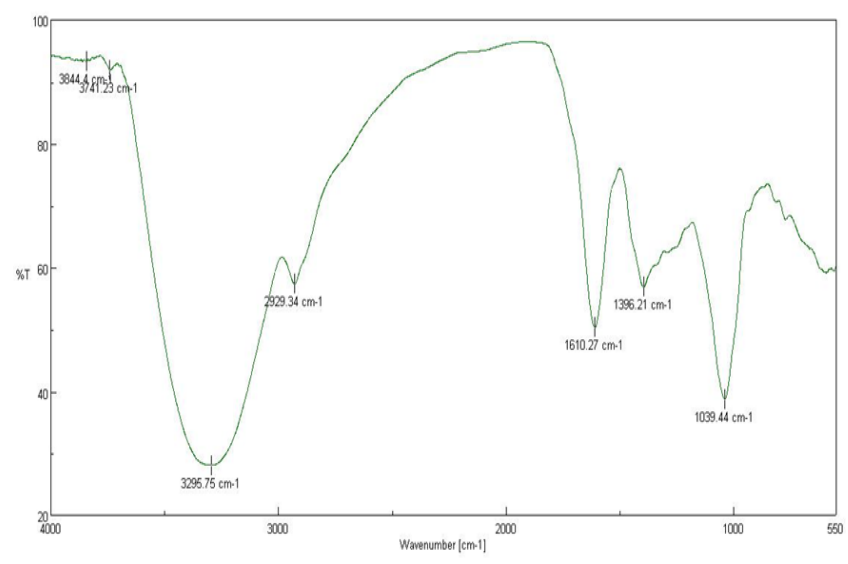

Fig. 4. FTIR Spectrum of Hibiscus dye

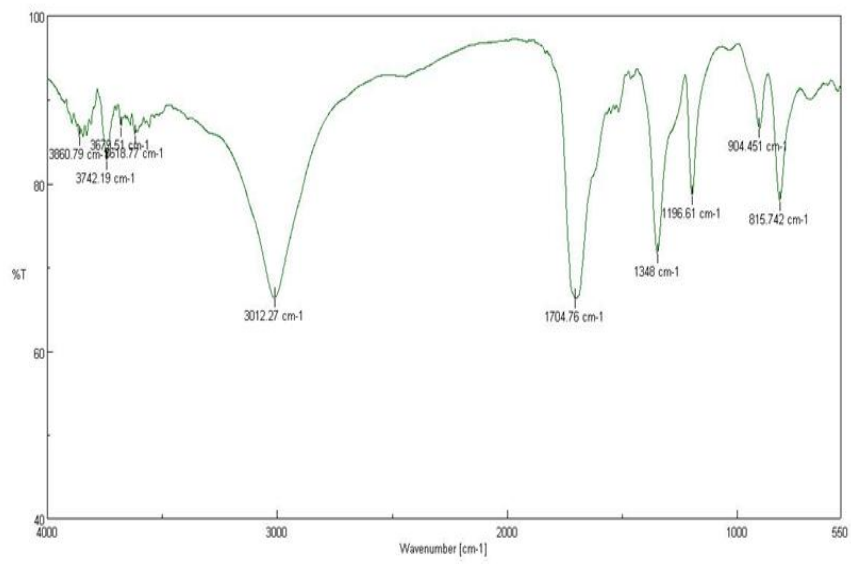

Fig. 5 FTIR Spectrum of Beetroot dye

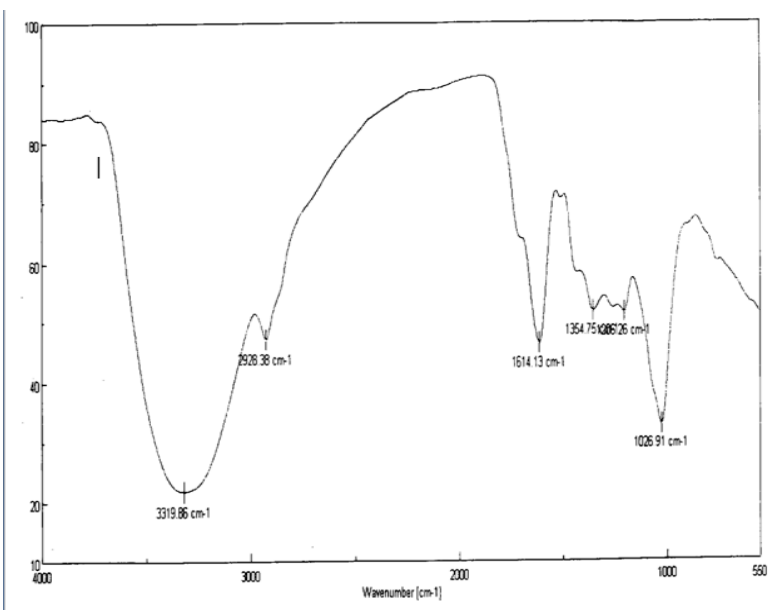

Fig .6. FTIR Spectrum of Mehanthi dye

\section{CONCLUSION}

The different types of plants dyes are extracted and characterized by FT-IR Spectroscopy. The dye present in turmeric is curcumin. The yellow dye in onion skins is made of a mixture of flavonoids: quercetin, Kempferol and quercetin-3-glucoside. Optuntia structures of the flavanols, Kempferol and Catechin. Hibiscus is Delphinidin 3-sambubioside. The major component of the dye extracted from Teak bark is Bixin and Beetroot is Betanin, betacyanin. The dye extracted from Henna leaves (Mehnthi), contains 2-Hydroxy-1, 4naphthoquinone.

\section{ACKNOWLEDGEMENT}

The authors would like to thank Chemistry Research Centre of PSN college of Engineering and Technology Tirunelveli, Tamil Nadu.

\section{REFERENCE}

[1] Bhattacharya $\mathrm{N}$, in Proceeding of convention of Natural Dyes edited by Deepti Gupta \& M.L Gulrajani, Department of Textile Technology, IIT Delhi, 1999, 134.

[2] Benencia F \& Courreges M C, Phytomed, 6 (2) (1999) 119.

[3] Bhattacharya S K, Chatterjee S M \& Dutta C, Man-made textiles in India, (2004) 85

[4] Bain S, Singh O P \& Kang K, Man-made textiles in India, 45(8) (2002) 315.

[5] Cristea D \& Vilarem G, Dyes and Pigments , 70, (2006), 238 
[6] Duff D G, Sinclair R S \& Grierson S, Textile History, 16 (1) (1985) 23-43

[7] Duff $D$ G, Sinclair $R$ S \& Stiriling $D$, Studies in Conservation 22 (1977) 161-169 Dedhia E M, Colourage, 45 (3), 1998, 45

[8] Dayal R \& Dobhal P C , Colourage, 48 (8) (2001) 33

[9] Dixit $S \&$ Jahan S, Man-made Textiles in India, 48 (7) (2005) 252.

[10] Gupta G, in Proceedings of 1st Convention on Natural Dyes (Ed-D Gupta \& M.L Gulrajani), Dept of Textiles Tech, IIT Delhi, 9th -11th December, (1999), 121

[11] Grover E, Sharma A \& Rawat B, International dyers, 190(10), (2005), 9

[12] Gupta D P, Gulrajani M L, Indian J Fibre Text Res, 18 (12), (1993), 202

[13] Saxena S, Varadarajan P V \& Nachane N D, in Proceeding of convention of Natural Dyes edited by Deepti Gupta \& M.L Gulrajani, Department of Textile Technology, IIT Delhi, 2001, 185.

[14] Sarkar D, Mazumdar K, Datta S \& Sinha D K, J Textile Assoc, 66 (2) (2005) 67.

[15] Sarkar D, Mazumdar K \& Datta S, Man-made Textiles in India, (1) (2006) 19.

[16] A.S. Fouda, A.A. Al-Sarawy, and E.E-Katori "Pyrazolone derivatives as corrosion inhibitors for $\mathrm{C}$-steel $\mathrm{HCL}$ solution," Desalination, vol.201, pp.1-13,2006.

[17] Fiala, A. Chibani, A.darchen, A. Boulkamh, and K. Djebbar, "Investigations of the inhibition of copper corrosion in nitric acid solutions by ketene dithioaccetal derivatives, "Applied Surface Science, vol. 253, no.24, pp.9347-9356,2007

[18] E. El Ouariachi, J. Paolini, M. Bouklah et al., "Adsorption properties of Rosmarinus of ficinalis oil as green corrosion inhibitors on C38 steel in $0.5 \mathrm{M} \mathrm{H} 2 \mathrm{SO} 4$," Acta Metallurgica Sinica, vol. 23, no. 1, pp. 13-20, 2010.

[19] A. O. Odiongenyi, S. A. Odoemelam, and N. O. Eddy, "Corrosion inhibition and adsorption properties of ethanol extract of Vernonia Amygdalina for the corrosion of mild steel in H2SO4," Portugaliae Electrochimica Acta, vol. 27, no. 1, pp. 33-45, 2009.

[20] K. Agarwal, Application of natural dyes on textiles, Indian Journal of Fibre \& Textile Research, 34, 2009, 384-399,

[21] Pierce, Are natural colorants good for your health? Journal of the Society of Dyers and Color, 109, 1993, No. 5-7.

[22] P. S. Vankar, Handbook on natural dyes for industrial applications, National Institute of Industrial Research, 2007

[23] A. Manhita \& T. Ferreira, Extracting natural dyes from wool, Anal Bioanal Chem, 2011, 1-14

[24] O. Korankye, Extraction and Application of plant dyes to serve as colorants for food and textiles, phd thesis, 2010.

[25] Irobechni, Analytical methods for the characterization of organic dyes in art work and in historical textile, Appl spectrosc rev, 44, 2009, 365-410.

[26] Rosenberg, Characterization of historic al organic dyestuffs by liquid chromatography - mass spectrometry, Analytical bioanol chemi. Journal, 391, 2008, 33-57.

[27] Z.C. Koren, Historico -chemical analysis of plant dyes tuffs used in textiles from ancient Israel, American chemical society Washington, 1995, 269-310.

[28] Z. Lauresen , Development of mild extraction methods for the analysis of natural dyes in textile of historical interests, Anal Bioanal Chem, 77, 2005, 2022-2015.

[29] J. Lee, Characterization of Natural Dyes and Traditional Korean Silk Fabric by Surface Analytical Techniques, www.mdpi.com/journal/materials, 6, 2013, 1-19. 10. R. Kanchana, Dyeing of Textiles. 